\title{
Postoperative cognitive dysfunction related to Alzheimer disease?
}

\author{
Rebecca M. Gerlach, MD, and Mark A. Chaney, MD
}

\footnotetext{
From the Division of Cardiac Anesthesia, Department of Anesthesia and Critical Care, University of Chicago, Chicago, Ill.

Disclosures: Authors have nothing to disclose with regard to commercial support.

Received for publication Oct 28, 2017; accepted for publication Oct 30, 2017; available ahead of print Jan 13, 2018.

Address for reprints: Mark A. Chaney, MD, Division of Cardiac Anesthesia, Department of Anesthesia and Critical Care, University of Chicago, Chicago, IL 60637 (E-mail: mchaney@ dacc.uchicago.edu).

J Thorac Cardiovasc Surg 2018;155:968-9

$0022-5223 / \$ 36.00$

Copyright (c) 2017 by The American Association for Thoracic Surgery

https://doi.org/10.1016/j.jtcvs.2017.10.113
}

Postoperative cognitive dysfunction (POCD) following cardiac surgery affects a substantial proportion of patients (up to $80 \%$ ) and consistently increases morbidity, mortality, and health care expenditures. Unfortunately, very little is known about POCD pathophysiology and diagnosis is challenging. Duan and colleagues ${ }^{1}$ from China shed some potentially useful light on this dark subject.

Duan and colleagues ${ }^{1}$ examined the potential link of glial cell line-derived neurotrophic factor (GDNF) and development of POCD in 80 patients undergoing elective valve replacement secondary to rheumatic heart disease. The GDNF protein is of particular interest because it is known to promote neuronal health and low GDNF levels are found in patients with Alzheimer's disease. ${ }^{2}$ GDNF also has neuronal regenerative properties and has demonstrated potential as a therapeutic treatment for certain neurologic diseases.

The prospective, observational study presented by Duan and colleagues ${ }^{1}$ examined patients undergoing hypothermic $\left(28^{\circ} \mathrm{C}-32^{\circ} \mathrm{C}\right)$ cardiopulmonary bypass. Trained physicians conducted a battery of 5 neurocognitive tests twice (1 day before and 7 days after surgery) and compared the results with those of 20 healthy volunteers tested in the same manner. GDNF immunoassays were performed from blood samples obtained at 4 time points (immediately before surgery and 1, 2, and 7 days after surgery).

The 80 patients were assessed for POCD using the Z-score, a previously defined (although somewhat nebulous) technique that assesses for a decrease in test performance from baseline while accounting for the expected improvement in score from serial testing in the same individual. ${ }^{4}$ The score is normalized by comparison with volunteer controls, which in this case, creates a problematic assumption that the same degree of test-retest change occurs in healthy volunteers as occurs in patients following a major surgical insult. Nevertheless, the blood levels of GDNF were lower in the POCD group (38 patients) compared with the non-POCD group (42 patients) at all time points. The change in GDNF levels on day 2 and day

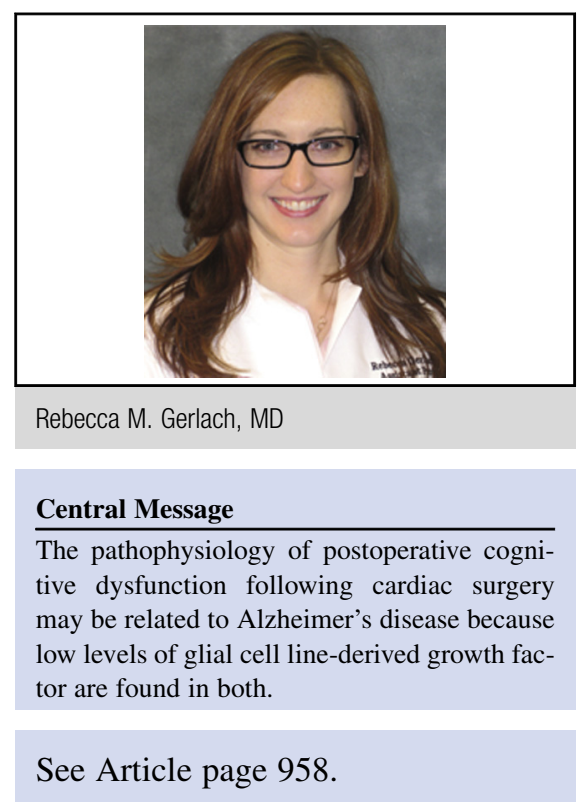

7 after surgery were particularly predictive of the development of POCD. Although there are significant limitations to this clinical investigation (limited detail about baseline clinical risk factors, differences between group education level, and lack of cerebrospinal fluid assessment), the results seem to implicate GDNF in POCD following cardiac surgery. The ability to use postoperative blood levels of GDNF to predict POCD (vs time-consuming neurocognitive testing) would be a useful tool.

This study ${ }^{1}$ raises many interesting questions for future research, particularly considering emerging data surrounding therapeutic interventions in Alzheimer's disease. ${ }^{3,5}$ Do low levels of GDNF continue to predict prolonged POCD beyond the immediate recovery period from surgery? Do GDNF levels increase back to baseline in patients whose POCD resolves? Is decreased GDNF in POCD a marker of the disease or the causative factor behind symptoms? Can POCD be prevented by increasing GDNF levels with currently available drugs such as amantidine ${ }^{6}$ or by exercise-induced increases in neurotrophic factors ${ }^{7}$ ? The answers to some of these questions may lead to important discoveries in understanding, and hopefully treatment of, the challenge of POCD.

\section{References}

1. Duan X, Zhu T, Chen C, Zhang G, Zhang J, Wang L, et al. Serum glial cell line-derived neurotrophic factor levels and postoperative cognitive dysfunction 
after surgery for rheumatic heart disease. J Thorac Cardiovasc Surg. 2018;155: 958-65.e1.

2. Straten G, Eschweiler GW, Maetzler W, Laske C, Leyhe T. Glial cell-line derived neurotrophic factor (GDNF) concentrations in cerebrospinal fluid and serum of patients with early Alzheimer's disease and normal controls. J Alzheimers Dis. 2009; 18:331-7.

3. Allen SJ, Watson JJ, Shoemark DK, Barua NU, Patel NK. GDNF, NGF and BDNF as therapeutic options for neurodegeneration. Pharmacol Ther. 2013; 138:155-75.

4. Moller JT, Cluitmans P, Rasmussen LS, Houx P, Rasmussen H, Canet J, et al. Long-term postoperative cognitive dysfunction in the elderly ISPOCD1 study.
ISPOCD investigators. International study of post-operative cognitive dysfunction. Lancet. 1998;351:857-61.

5. Sampaio TB, Savall AS, Gutierrez MEZ, Pinton S. Neurotrophic factors in Alzheimer's and Parkinson's diseases: implications for pathogenesis and therapy. Neural Reg Res. 2017;12:549-57.

6. Zhang J, Tan H, Jiang W, Zuo Z. Amantadine alleviates postoperative cognitive dysfunction possibly by increasing glial cell line-derived neurotrophic factor in rats. Anesthesiology. 2014;121:773-85.

7. Griffin ÉW, Mullally S, Foley C, Warmington SA, O'Mara SM, Kelly ÁM. Aerobic exercise improves hippocampal function and increases BDNF in the serum of young adult males. Physiol Behav. 2011;104:934-41. 